\title{
Organophosphorous Pesticides Exacerbate the Demographic Consequences of Intersexual Selection in Fish
}

\author{
Irene BarbosaValero' ${ }^{1}$ Omar Arellano-Aguilar² \\ and Constantino Macías Garcia ${ }^{1,3}$ \\ 1Universidad Nacional Autónoma de México-UNAM, Departamento de Ecología Evolutiva \\ ${ }^{2}$ Universidad Nacional Autónoma de México-UNAM, Departamento de Medicina \\ Genómica y Toxicología Ambiental \\ México
}

\section{Introduction}

In the last 150 years, the human population has increased very rapidly in part due to the generalised use of agrochemicals, which enabled the development of intensive farming of food crops. Large monocultures are particularly vulnerable to pests, thus pesticides became widely used since the 1930's to aid producing larger crops. However, within a few decades the collateral negative effects of pesticides on the environment became apparent (Nimmo \& McEwen, 1994). The first paper on adverse effects of pesticides was published in the early 1940 's, but it was not until the 1960s that the Rachel Carsons review showed strong evidence of the environmental risk from the use of pesticides, particularly organochlorines such as the DDT (Nimmo \& McEwen, 1994). This led to the search for alternatives, and in recent decades the organophosphorous (OPs) pesticides have become more used due to their short persistence in the environment and their high toxicity. These are lipophilic substances that penetrate through skin, and depending on their chemical structure are divided into phosphorotiates (e.g. methyl parathion, parathion, diazinon) and phosphoroditioates (e.g. malathion, dimetoate and azinfosmethyl). The biotransformation and activation pathways of OPs have been extensively reviewed (Jokanović, 2001). Mainly, OPs interfere with transmission of nerve impulses as they inhibit the activity of serine esterases, particularly the catalytic activity of acetilcholinesterase (AChE). The chemical reactions occur largely in the liver, where the $\mathrm{OP}$ thioeter group is oxidized to the oxon metabolite $(\mathrm{P}=\mathrm{S} \rightarrow \mathrm{P}=\mathrm{O})$ by the action of citochrome P450 monooxygenases. After this biotransformation the OPs can bioaccumulate, or they can become immediately toxic. Because of their chemical affinity, OPs bioaccumulate in adipose tissues, muscle, glands, gonads and organs such as the liver, kidneys and brain (Vittozzi et al., 2001). Fatty tissue stores both the original form and the oxon metabolites. This process reduces the concentrations of free OPs in blood, yet during periods of starvation or stress, when stored fat is mobilized to supply metabolic energy, the OPs are released, leading to re-intoxication (Jokanović, 2001). Toxicity itself can occur in two ways: inhibition of

${ }^{3}$ Author for correspondence 
acetylcholinesterase, and citotoxic effects on immune cells (Vittozzi et al., 2001). Inhibition of AChE occurs through the interaction between $\mathrm{P}=\mathrm{O}$ and the serine hydroxil group at the enzyme's active site. As AChE, is responsible for the hydrolysis of the neurotransmitter acetylcholine (which stimulates postsynaptic response in the nervous systems and in the neuromuscular junction; Jokanović, 2001), the enzymes inactivation disrupts the action of the nervous and neuromotor systems. Citotoxicity is the result of oxidative desulphuration of OPs in which free radicals or reactive oxygen species (ROS) are released. Li (2007) proposed this mechanism because OPs affect directly the immune system by citotoxicity on T-lymphocytes. Moreover, the high concentration of free radicals and ROS produces protein and lipid oxidation, resulting in damage to cell membranes or even DNA.

Organophosphorous pesticides cause several physiological effects -characterised by a diversity of symptoms- depending on time exposure and chemical concentration. Pesticides act at molecular level within the organisms, yet these interactions can lead to a cascade of effects, from the biochemical through the organism, the population, and up to the ecosystem levels (Walker et al., 2006; Fig. 1.). The physiological effects of OPs have been severally described. They can cause neurotoxic damage by AChE inhibition as shown in the mosquitofish (Gambusia affinis; Boone \& Chambers, 1996), induce chromosome aberrations such as those observed in the green chromide (Etroplus suratensis), a cichlid fish from India and Sri Lanka (Das \& John, 1999), and compromise growth and neural development in mammals (e.g. Abu-Qare et al., 2000). Citotoxic effects and damage to organs such as liver, intestine and gills have also been reported (Fanta et al., 2003), and can lead to reduced behavioural performance. In developing organism, exposure can result in a failure to attain normal weight and in reduced nestling survival (as in nestling European starlings Sturnus vulgaris; Parker \& Goldstein, 2000).

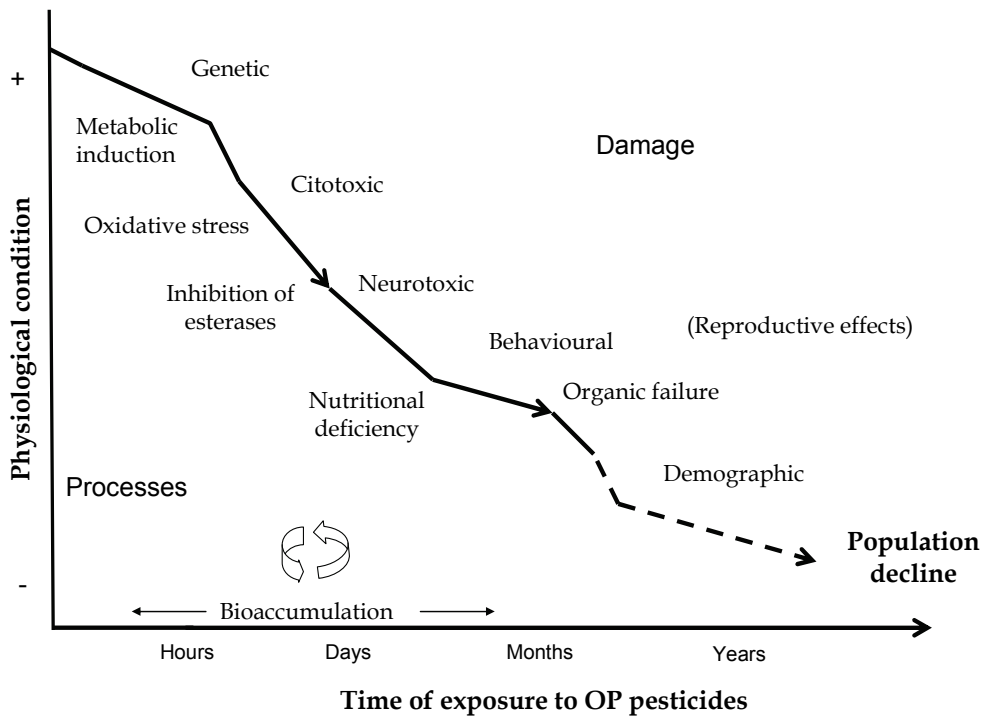

Fig. 1. Acute or chronic exposure to organophosphorous pesticides induces metabolic changes that produce a cascade of effects in the complete organism; depending on the duration of the exposure and on the pesticide concentration, the physiological condition of the exposed organisms decreases and can lead to population decline. 
Perhaps the most visible effects of sub-lethal intoxication with OPs are, at the individual level, changes in the normal behaviour (see Welsh \& Hanselka, 1972 and Castillo et al., 2002 for early and recent reports respectively); and, at the population level, demographic decline such as that reported by Sarma et al. (2001) for a rotifer population whose growth rate declined following continuous OP exposure. Although both the general mechanisms of action of OPs and their acute effects are well known, little has been documented on the consequences of sub-lethal concentrations and of chronic exposure. By definition, these processes would have less obvious effects than chronic/acute exposure and may only become apparent in the long run at the demographic level. Here we show evidence of such subtle effects; we deal particularly with a behavioural-ecological process -sexual selectionwhich is likely to be disturbed by sub-lethal exposure. In species in which male mating success depends on the production and display of costly ornaments and reproductive behaviours, the exposure to insecticides, organophosphorous or otherwise, may lead to scarcity of attractive males and thus to a reduction of the population size.

\subsection{Sub-lethal exposure and behaviour}

Behaviour is an aspect of the phenotype which integrates processes occurring at various levels, from cell receptors to neuromotor mechanisms, into coordinated responses whose ultimate function is to promote the individual's fitness. It is this integrative nature that has led several authors to propose that behaviour can be used to detect environmental changes in nature, such as those promoted by human activities. For instance, Little (1990) indicated that behaviour provides a "unique toxicological perspective", because it bridges the gap between the biochemical approach traditionally favoured in toxicology, and the ecological consequences of pollution. This view was more recently repeated by Walker et al. (2006) who mentioned that behaviour represents the diversity of biochemical and physiological processes. Indeed, being a biologically meaningful response, behaviour provides ecological realism to our assessments of anthropogenic impact in nature.

The term "behaviour" encompasses a very large amount of diverse phenomena. It includes 1) events which are mostly reactive, such as tropisms (the translation of one organism towards an attractant like sugar or light), predator avoidance, breathing (e.g. the opercular movements of fish, whose rhythm is partly determined by oxygen concentration in the water), panting and other simple thermoregulatory activities, etc. It also includes 2) more pro-active activities such as foraging (active search for food using endogenous rules, rather than merely responding to external stimuli), building of nests and other structures (an activity that also requires endogenous drives) or courtship displays, whose orientation and timing may be determined by external stimuli, but which follow endogenous rules that are in many cases completely unrelated to the immediate environmental conditions (see Baerends 1976; Lenher, 1996). The first, more "automatic" reactive behaviours are normally simple in structure, relatively invariant within species or populations, and easy to record. Also, the performance of those simple behaviours is often rather directly related to the organism's condition (e.g. a physiologically impaired animal would display more sluggish escape reactions than a healthy individual). It is therefore clear why behavioural toxicology relies heavily behaviours belonging to this category, particularly when dealing with acute/chronic exposure.

By contrast, behaviours in the second category are usually complex in nature, quite variable between individuals and populations, and consequently difficult to record in a standardised manner. Nevertheless, it is these behaviours that are often more closely related to important 
components of the species' life histories. During acute exposure pro-active behaviours are unlikely to express themselves, and thus would be of no use to the toxicological research. Yet organisms exposed to sub-lethal intoxication would still display e.g. pro-active foraging or courtship, albeit not with the vigour, frequency or efficacy as non-exposed organisms. Other, less obvious but equally insidious effects of pollutants on proactive behaviours may include interference with intra-specific recognition (e.g. Fisher et al., 2006) or abnormal sexual performance through disrupting hormonal balance (Toft et al., 2003; see Markman et al., 2008 for an example where male performance is enhanced). It is in this context that recording the expression of such behaviours can alert of potentially negative consequences of exposure to natural populations. We shall review in the following sections the effects of pollutants on behavioural performance and their implications at a demographic level.

The chemical industry has produced more than 500 compounds known to cause behavioural toxicity, which are classified as narcotics, excitatory agents, biochemical disruptors, cholinesterase inhibitors, reactive chemicals, central nervous system seizure agents and endocrine disruptors (details in Barron, 2002). The effects that have been associated with these chemicals include hyperactivity syndrome, paralysis, loss of coordination, tremors, ataxia, irritant responses, lethargy, etc., (Barron, 2002). Most of these effects have been observed following acute exposure or at high concentrations, and as mentioned above, all involve simple, automatic behaviours. To date, only a few studies have systematically investigated the behavioural consequences of exposure to sub-lethal concentrations. This is probably because the dominant paradigm in toxicology has been the dose-effect curve and the $\mathrm{LC}_{50}$ value, calculated as the concentration at which $50 \%$ of exposed individuals die. It is obvious that studying the consequences of exposure to $\mathrm{LC}_{50}$ provides an objective, repeatable experimental condition that can be compared across studies and has a clear definition. Yet before dying, the organisms experience different states of intoxication, by definition all deemed "sub-lethal", which differ in their symptoms and in their biological significance. Walker (1998) conceptualized the dose-effect curve as a function with hypothetical limits that represent biological responses. Between the hypothetical limits " $c$ " (where compensatory mechanism can arrest the onset of overt disease) and " $r$ " (beyond which repair mechanisms cannot longer prevent pathological damage), the behavioural symptoms enlisted above can be observed and are linked with impaired physiology and pathological damage (Fig. 2). However, there are less obvious behavioural modifications that are not necessarily directly linked to neurotoxicity. For example, as part of the M74 syndrome characterised by high mortality of salmon (Salmo salar) fry in the Baltic Sea (recorded between 1974 and 1993 and possibly brought about by exposure to organochlorine pesticides), both female and male adult fish showed abnormal swimming behaviour and general lethargy. During the early stages, fish showed anoxia, low levels of carotenoids and antioxidants such as a-tocopherol and ubiquinone (Börjenson \& Norrgren, 1997). In addition, Baltic salmon presented induction of catalytic activity of cytochrome P450 enzymes and low levels of thiamine, which produced oxidative stress and "deficient behaviour". Although in cases such as that of the M74 syndrome the link between behavioural and physiological impairment is evident, it is still debated whether animal behaviour is a useful parameter to incorporate in toxicological tests. The main arguments against are that field observations are difficult to quantify and that the best studies are focused on behaviours that are of little ecological relevance (Walker et al., 2006). The first criticism is easily rebutted, as it can be overcome with improved recording methods (including new remote-sensing technologies). The second argument highlights the need to 
identify those relevant behaviours which are likely to be affected by sub-lethal exposure and to influence fitness. As we saw above, complex, pro-active behaviours such as foraging and courtship are good candidates to unmask biologically relevant effects of sub-lethal exposure in natural populations.

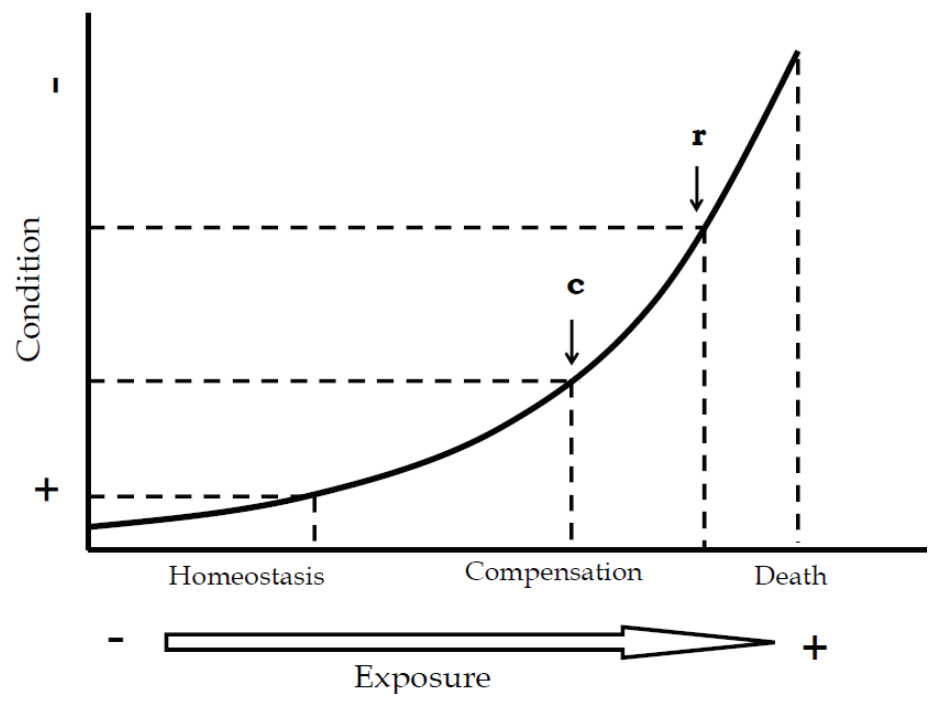

Fig. 2. The majority of behavioural changes registered during chemical exposure occur between " $c$ " and " $r$ ", which define the conditions where disease can be fought and pathological damage averted by compensatory and repair mechanisms (modified from Walker, 1998).

\subsection{Sub-lethal exposure of OPs and intersexual selection}

There is a recent trend to look into the effects of pollutant exposure on animal behaviour. Particular attention have received organophosphorous pesticides because these are neurotoxic and lipophilic chemicals which inhibit acethylcholinesterase (AChE) catalytic activity and detrimentally affect the expression of behaviour (see above). Their reputedly short persistence in nature and their high toxicity were the reasons why OPs substituted in the last decades the organochlorine pesticides formerly used in agriculture. We have learned that OPs can persist at low concentrations for more than 200 days in freshwater ecosystems (Bonderenko \& Gan, 2004). This is a short persistence in nature compared to the decades of the DDT half life, but even if present for only a few days, OPs become available for- and are incorporated (bioaccumulate) into aquatic fauna (De la Vega-Salazar et al., 1997), often with adverse consequences.

One obvious way in which behaviour is influenced by pesticides is through their teratological effects during embryogenesis. For instance, malformations produced by sublethal exposure to OP during embryonic development also cause deficient swimming (Bonfanti et al., 2004; Arellano-Aguilar \& Macías Garcia, 2009). Pesticides can also have direct adverse effects on swimming behaviour when these interact with AChE activity, as is the case of OPs, or when they interfere with other and physiological processes (see Jones \& Reynolds, 1997). For instance, Boone \& Chambers (1996) demonstrated that more than $70 \%$ 
of AChE activity is inhibited in the mosquitofish (Gambusia affinis) between 4 and $12 \mathrm{hr}$ after sub-lethal exposure to OP pesticides such as methyl parathion $(8 \mu \mathrm{g} / \mathrm{ml}$ concentration), chlorpyrifos $(0.1 \mu \mathrm{g} / \mathrm{ml})$ and parathion $(0.1 \mu \mathrm{g} / \mathrm{ml})$, and the physiological damage was accompanied by abnormal swimming behaviour. In fact, behavioural damage can become evident as quickly as the earliest symptoms of physiological damage. For instance, in the armoured catfish Corydoras paleatus, gill damage is evident one hour after exposure to 0.083 $\mu \mathrm{g} / \mathrm{g}$ of methyl parathion, coinciding with the onset of a decrease in swimming activity that reaches between $30 \%$ and $40 \%$ three days later. Damage to the intestine and liver tissues becomes apparent only after four hours of exposure (Fanta et al., 2003). It is clear that a reduced motor performance can influence survival, yet in most cases it happens only after long-term exposure or following acute intoxication. More subtle behavioural effects are likely to follow sub-lethal exposure. We expect that organisms exposed to low concentrations of OPs will be more vulnerable to predation and their foraging behaviour will be sub-optimal. Another hypothesis is that OPs should interfere with mating behaviour. Surprisingly, in spite of having been proposed more than a decade ago (Jones \& Reynolds, 1997), this possibility has seldom been investigated. In the following sections we present some recent results of our research on the links between exposure to insecticides and sexual performance. First we review the basic concepts relating sexual displays, ornamentation, male condition and female mate choice.

Charles Darwin (1871) developed the concept of intersexual selection (normally female choice) to explain the existence of structures in the males that appear to defy natural selection. Three mechanisms have been proposed to explain why ornaments can evolve through female choice: direct benefits, indirect benefits, and exploitation of female sensory biases (see review in Andersson 1994). Males may advertise with the quality of their ornaments their capacity to provide direct benefits to females such as food, nutrients, parental care or good territory. The term "indirect benefits" refers to two different processes: runaway sexual selection (Fisher, 1930), and handicap (Zahavi, 1975) or "good genes" (Andersson in 1994). The handicap mechanism proposes that phenotypic quality is to some extent based on genetic variants which correlate with the expression of secondary sexual characters. The runaway model proposes that the genes responsible for the production of the ornaments and those responsible for the female preferences are jointly inherited, although their phenotypic effects are sexlinked. According to this model it is not necessary that the genes responsible for the ornaments affect survival or fecundity (Futuyma, 1998). In the case of "indicator mechanism," the attractive male traits reflect genetic/health condition (condition-dependent indicator models) and are preferred by the females because they provide genetic benefits for her offspring. Thus, male traits correlate positively with male fitness (Andersson \& Simmons, 2006). Finally, the sensory bias mechanism proposes that females are particularly responsive to certain attributes of the environment, for instance food items, which are imitated by the male ornaments (Andersson \& Simmons, 2006). Of course, these mechanisms are not mutually exclusive.

The environment normally plays a significant role in the outcome of mate choice. This is in part because ornaments can evolve to signal male genetic or environmental quality (or both; Cotton et al., 2004). For instance large body size in both females and males is favoured by sexual selection because large traits generally correlate with fecundity or fertility (Curtis \& Stoddard, 2003; Basolo, 2004). Yet, body size often varies with environmental factors such as temperature, food availability, social interactions, geographic distribution (Yom-Tov \& Geffen, 2006), thus adaptive mate choice tracking changes in body size would uncover the environmental factors responsible for the size change, such as pollution with pesticides. 
The consequences of pollution in water bodies are diverse, but can be grouped into two categories: 1) changes in abiotic parameters related to water quality such as transparency, dissolved oxygen and nutrients, and 2) presence of toxic substances. For example, eutrophication produces an increase in turbidity in which visual components of mate choice are affected. Seehausen et al. (1997) demonstrated that eutrophication has provoked biodiversity loss amongst native cichlid species in Lake Victoria because a reduced transparency has affected sexual selection based on coloration, which is responsible for maintaining reproductive isolation among sympatric species. Eutrophication also reduces the concentration of oxygen, and Reynolds \& Jones (1999) observed that low oxygen condition produces a reversal of female mating preference in common gobies (Pomatoschistus microps). At normal concentrations of dissolved oxygen, goby females prefer males that already have eggs under their parental care over those without eggs, but female choice is reversed at 35\% dissolved oxygen, presumably because large egg masses demand more oxygen than small clutches. Chemical compounds can also interfere directly with female choice in relation to their mechanism of action. For example, endocrine disrupting chemicals such as $17 \beta$-estradiol $\left(\mathrm{E}_{2}\right)$, 17a-ethinylestradiol, 4-tert-octylphenol (4OP), phthalates and alkylphenols interact with estrogenic receptors in the brain, causing reproductive behavioural changes, which would not be necessarily related to female choice. Bjerselius et al. (2001) observed a reduction in following behaviour in male goldfish (Carassius auratus) after exposure to $1 \mu \mathrm{g} \mathrm{E}_{2} / \mathrm{L}$ and $10 \mu \mathrm{g} \mathrm{E}_{2} / \mathrm{L}$. An opposite effect was found by Toft \& Baatrup (2003), who reported an increase in courtship behaviour in guppies (Poecilia reticulata) exposed to $100 \mu \mathrm{g} 4 \mathrm{OP} / \mathrm{L}$.

In the case of neurotoxic compounds such as OPs, several studies have reported effects on swimming behaviour (see above), however Arellano-Aguilar \& Macías Garcia (2008) reported for the first time the non-neurotoxic effects of OP pesticides on intersexual selection in the Amarillo fish (Girardinichthys multiradiatus). This report showed that sublethal exposure to methyl parathion during embryonic development affects the condition of adults and their attractiveness to choosy females; particularly male ornaments (size and colour) and courtship display (details of experiment below). Following Arellano-Aguilar \& Macías Garcia (2008) report, Cothran et al. (2010) could not find evidence that another OP, malathion, at sub-lethal concentration affects female mate choice in American amphipods (Hyalella sp.). However, there are good reasons to expect that any chemical compound that interfere with sexual signal expression would negatively influence mate choice. Accordingly, Secondi et al. (2009) found that realistic nitrate concentrations affect the sexual trait size in newts (Triturus helveticus), reducing the sexual attractiveness of males. Female newts showed a clear preference for unexposed males (Secondi et al, 2009), a behavioural response similar to that observed in the experiment with Amarillo fish. Clearly more research is needed to understand the ecological and evolutionary implications of the interaction between low concentrations of pollutants and sexual selection.

\subsection{Demographic consequences}

The demographic consequences for a population may not be apparent at the time of exposure, but become evident in the long run, even after several generations have passed. Pollutants may perturb the population dynamics or even irreversibly impair its survival. Walker et al. (2006) mentioned that in chronic pollution, populations of some species might decline and eventually become extinct, or they may recover, persist or even increases. To improve our capability to predict the possible outcome of pollution it is necessary to know 
the dynamic of the focal populations, through gathering accurate estimates of some demographic parameters such as sex ratio, age structure, age-specific fecundity and mortality, and rate of increase or growth rate. These parameters can be used to make reasonable predictions of the populations' growth or decline, and to determine the impact of particular life stages on the demographic behaviour of the population. They are obtained by directly counting (or sampling) the individuals and tallying their survival, mortality and fecundity. From those data indirect measures such as the sex ratio, the proportions of new born, young and adults and the population age structure are then calculated and used to estimate growth rates (Skalski et al., 2005).

One of the simplest ways to verify if a population is increasing or decreasing is subtracting the number of the individuals at a posterior time $\left(\mathrm{N}_{\mathrm{t}+1}\right)$ against the current population size $\left(\mathrm{N}_{\mathrm{t}}\right)$. The difference is the number of individuals added or lost in the next generation. It is to be expected that the number of individuals some time in the future $\left(\mathrm{N}_{\mathrm{t}+1}\right)$ is affected by the population size $(\mathrm{N})$, the number of births and of deaths in the current generation. It would be also necessary to determine whether there are immigrants to add and/or emigrants to subtract from the current population size, but it is often assumed for simplicity that populations are closed and that no immigration or emigration takes place.

In continuous population growth, where births (B) and deaths (D) are constantly occurring, the rate of change in population size during a given period $(d t)$ is:

$$
d N_{t} / d t=B-D
$$

The instantaneous birth rate $(b)$, or the number of births per individual per unit time is calculated by the total number of births divided by the total numbers of individuals, $b=N / B$. Similarly, the instantaneous death rate $(d)$ is the division of the total number of deaths between the individuals, $d=N / D$. From these equations;

$$
d N_{t} / d t=(b-d) N
$$

Thus $(b-d)$ represents the intrinsic or instantaneous rate of increase $(r)$, which is the per capita rate of change, or growth rate, of the population per unit time. The value of $r$ is important as it reflects the vitality and the potential of the population to increase. If the intrinsic rate of increase $r>0$, the population increases, if $r=0$, the population size remains stationary and $r<0$ indicates that the population is decreasing.

$$
d N_{t} / d t=r N
$$

A modification of the above is necessary when birth and death rates are not continuous. In many species births are discrete events that occur one or more times a year, at specific times or seasons (e.g. in the spring). In those species deaths may also occur at discrete periods in the year. In these cases $r$ should be replaced by the finite rate of change $(\lambda)$ which represents the proportional change in abundance from time $t(N t)$ to time $t_{+1}\left(N t_{+1}\right)$. The finite rate of increase $(\lambda)$ is the growth rate per period of time (usually a year) and it is calculated as follows:

$$
\lambda=N t_{+1} / N t
$$

Just as before, $\lambda>1$ indicates that the population is increasing; $\lambda=1$ indicates a stationary population and $\lambda<1$ indicates a decreasing population. For example, $\lambda=1.17$ represents a $17 \%$ 
of increase in the population between $t$ and $t+1$.There are several methods to calculate $r$ and $\lambda$, including the Lotka equation based on fecundity rate, and population projection Leslie matrices based on survival rates (Leslie 1945; Skalski et al., 2005).

These parameters $(r$ and $\lambda$ ) are used commonly to describe the population growth and to compare growth rates among populations of the same or different species.

$$
\lambda=e^{r} \text {, or equivalently, } r=\ln \lambda
$$

To characterise demographic parameters such as absolute growth rates ( $r$ and $\lambda)$ is not enough to ensure the conservation of a population. This also requires knowledge of the genetic status of the population, including how much genetic diversity it harbours, what is the degree of inbreeding amongst its members, whether it is subject to genetic drift, its mutation load and its effective population size (related to the mating system). The effective population size $\left(N_{e}\right)$ is a crucial attribute: it is a genetic measure of the number of individuals needed to maintain the same genetic diversity between generations. As it is directly related to the rate at which genetic diversity is lost, $N_{e}$ also measures the rate at which genetic drift affects the population (Rieman \& Allendorf, 2001). In general, quantifying the amount of genetic diversity within a population or species is of the utmost importance in conservation genetics (Crandall et al., 1999), and no other genetic parameter affects the population demography as much as $N_{e}$, which is why the concept of effective population size has played an important role in the conservation genetics of endangered species.

Populations often have unequal numbers of males and females mating and contributing to the next generation. But, regardless of the total number of individuals, both sexes contribute an equal number of genes (Allendorf \& Luikart, 2007). The effective size of a population with unequal numbers of males and females mating randomly is calculated as:

$$
N e=4 N m N f / N m+N f
$$

Where $N m$ and $N f$ are the quantity of breeding males and females, respectively. Therefore, the effective population size $\left(N_{e}\right)$ is slightly smaller than the absolute population size $(\mathrm{N}$; Kimura \& Crow, 1963). On the other hand, if there is sexual selection acting on the population, where mating is biased in favour of only a fraction of the members of one sex, one of the consequences is an even greater reduction of the number of reproductive adults that contribute to the next generation.

Although sexual selection reduces the probability that deleterious mutations get fixed (because fit individuals are chosen by females attracted by their ornaments), it also affects the population genetic structure by reducing the level of heterozygosity (Kimura \& Crow, 1963; Futuyma, 1998). Strong directional selection means that some alleles become fixed and in a short time the population becomes monomorphic as it loses the additive genetic variance underlying the expression of traits (including those used in mate choice; Merilä \& Sheldon, 1999). In those circumstances genetic diversity would be strongly influenced by inbreeding, genetic drift and genetic bottlenecks (Price, 2005), and populations would be therefore more vulnerable to mutation loads and demographic stochastic fluctuations (Kimura et al., 1963). For instance, Bailey et al. (2007) explored the genetic variability of wild and captive populations of two fish species with intense sexual selection. They found that low effective population size contributes to increasing the risk of local extinction. The effect is more severe when anthropogenic factors such as pollution, introduction of exotic species 
or overfishing are also present because both the population size and $N e$ are affected. In the next section we describe a project designed to understand the mechanism that may reduce $\mathrm{Ne}$ in a species under intersexual selection when it is also exposed to pollutants. Ecotoxicological studies have focused on demographic changes, using population growth rate as the key measure of the possible long-term effects of pollution. We attempted to gather evidence to support our view that the concept of effective population size $\left(N_{e}\right)$ plays an even more important role in the management and conservation of threatened species.

\section{A case of study}

\subsection{The organophosphate methyl parathion and the fish Girardinichthys multiradiatus}

We shall illustrate how the exposure to an orgonophosphate -methyl parathion (MeP)- can exacerbate the demographic consequences of intersexual selection in the Mexican fish Girardinichthys multiradiatus. First we will briefly describe the peculiar attributes of the focal species and the pollutant involved. Then we will describe the different levels at which MeP adversely affects this fish. We will demonstrate how pesticides can affect the individual's phenotype, specifically the male ornaments, and how this consequently affects their attractiveness. We will then look into the effects at the population level; we will show the immediate demographic consequences and those that take place over successive generations of MeP exposure. Our data are mostly the result of experiments in which fish were exposed to different concentrations of MeP administered at different life stages. The study was carried out in a paradigm of artificial selection in a captive environment.

Our model is the topminnow Girardinichthys multiradiatus. This is a small fish that belongs to the Mexican Goodeidae, a group of viviparous fish in which sexual dimorphism is the norm. Males have large and more colourful fins than females and exhibit a complex courtship display (Macías Garcia, 1994). Females mating preferences are based on visual attributes like sexually dimorphic median fins, dimorphic colours and colour patterns (especially the yellow colour of the fins) and conspicuous courtship dances (Macías Garcia and Saborío, 2004). Fish in this species can detect UV light, and body reflectance in this wavelength is used also in female mate choice (Macías Garcia and Burt de Perera, 2002). Girardinichthys multiradiatus inhabits shallow areas in lakes, wetlands, streams and dams in the upper Lerma basin on the Mexican Central Plateau (Macías Garcia, 1994; Uribe, 2005). Its geographic distribution is restricted to about 11 sites (including streams and rivers) in the region of the Country where economic and industrial development is growing at a faster rate, besides being occupied in ca. $55 \%$ by agricultural activities (SNIARN 2006). Both their restricted distribution and reproductive biology -including viviparity and stringent female mate preferences- predispose the Mexican Goodeidae (or Goodeinae) to suffer from environmental fragmentation and other anthropogenic influences. In fact the principal factors of population decline in this family are desiccation and habitat destruction. Additionally, eutrophication, introduction of exotic species and pollution are also responsible for the ongoing increase in the rate of local extinction (De la Vega-Salazar \& Macías Garcia, 2005). The Goodeinae encompass some 16 genera with ca. 42 species, of which 22 are in some category of risk (8 endangered, 9 threatened, 3 in extreme danger of extinction and 2 extinct in nature; Contreras-Banderas, 2005; De la Vega-Salazar et al., 2005). The International Union for the Conservation of Nature IUCN Red list (1998) considers G. multiradiatus as vulnerable.

Through their natural range Goodeine fish are exposed to several pesticides, including the insecticide methyl parathion (MeP). This is an organophosphate largely used on a number 
of economically important agricultural crops such as cotton, soybean, corn, wheat, rice and bean (Garcia et al., 2003). The MeP used as pesticide reaches the ground and through percolation gets into the water bodies. $\mathrm{MeP}$ has a combination of chemical and physical properties that make it soluble in most organic solvents and also in some inorganic compounds, which is why this pollutant can easily enter into the aquatic systems. Girardinichthys multiradiatus is exposed to MeP in the field, where pregnant females show a negligible concentration in their tissues, about one order of magnitude below that in the tissues of the embryos they carry (De la Vega-Salazar et al., 1997).

\subsection{What are the effects of early sub-lethal exposure of MeP in G. multiradiatus?}

Two experiments were carried out to assess whether G. multiradiatus is negatively affected when exposed to sub-lethal concentrations of MeP; both involved contaminating a group of individuals with $\mathrm{MeP}$ and comparing the effects with a control group. The experimental design was planned a priori to reduce as much as possible the sources of variation and to increase the power of the analysis. Fish were maintained in aquaria at $25 \pm 2^{\circ} \mathrm{C}$ and under a $12 \mathrm{~h}$ dark $/ 12 \mathrm{~h}$ light photoperiod. In the first experiment (part two) we used a paternal halfsib protocol because we presumed that secondary sexual traits are heritable in this species. In the first experiment we used the second generation of fish collected in the wild (at San Juanico; $19^{\circ} 55^{\prime} \mathrm{N}, 9^{\circ} 47^{\prime} \mathrm{W}$ ), which had been kept in outdoor ponds at the Institute of Ecology-UNAM, Mexico (details in Arellano-Aguilar \& Macías Garcia, 2009).

First we calculated the $\mathrm{LC}_{50}$ and the bioaccumulation curve by feeding the fish $0.1 \mathrm{~g}$ of spiked food per day. Individuals at the start of the experiment were of the same age, weight and length. We used a gradient of MeP concentrations (0.001-0.165 $\mu \mathrm{g} \mathrm{MeP} / \mathrm{g}$ dry weight of food) for 30 days, and compared the effects with control fish kept under the same conditions and fed un-spiked food. Fish were measured $(\mathrm{mm})$ and weighed $(\mathrm{g})$ at the beginning and at the end of the experiment, and growth was calculated as the percentage of initial body length ([final length-initial length/initial length] $x$ 100). As reported originally (ArellanoAguilar \& Macías Garcia, 2009) the accumulation of MeP in adult G. multiradiatus follows a dose-dependent relationship. Fish exposed to concentrations of $0.008,0.02$ and $0.04 \mu \mathrm{g}$ of $\mathrm{MeP}$ for 30 days showed a reduction in size and weight. In addition, $\mathrm{MeP}$ was lethal at 0.165 $\mu \mathrm{g} / \mathrm{g}$. Bioaccumulation of MeP was measured in fish from each concentration using gas chromatography. This allowed us to determine the amount of MeP that should be added to the food given to pregnant females in order to mimic the concentrations reported in wild fish (De la Vega-Salazar et al., 1997). This procedure did in turn enable us to evaluate the consequences of pre-natal exposure to realistic concentrations on adult reproductive performance. As expected from sub-lethal concentrations, pregnant females exposed to $0.005,0.01$ and $0.1 \mu \mathrm{g} / \mathrm{g}$ did not show any negative effect, but they delivered varying proportions of malformed offspring. The main teratogenic effect was spinal cord malformation (scoliosis), which could be a consequence of inhibition of AChE during embryonic development. Around $60 \%$ of the total offspring exposed via mother to $0.005 \mu \mathrm{g} /$ $\mathrm{g} \mathrm{MeP}$ was apparently normal and survived to adulthood.

\subsection{Are there consequences of early MeP in adult fish?}

We examined the morphology and behaviour of adult fish which had been prenatally exposed to realistic concentrations of MeP. Adult males were presented with one matchedpair of non-pregnant females each. After 10 days, females were isolated in independent 
tanks, where they remained until parturition. One female from each pair was fed food containing a concentration of $0.005 \mu \mathrm{g} \mathrm{MeP} / \mathrm{g}$ (dry weight) and the other female was feed uncontaminated food. Shortly after birth each newborn brood was transferred to a MeP-free 401 aquarium until sexes could be distinguished, when each individual was isolated in cylindrical compartments and placed in single-sex aquaria. Survival of newborn offspring prenatally exposed to $0.005 \mu \mathrm{geP} / \mathrm{g}$ was comparable to that of control fish up to adulthood (90 days of age), yet morphology and behavioural performance were compromised. Dimorphic fins were less developed, colour duller, and reproductive behaviour (frequency and duration of courtship displays ) less energetic in exposed than in control fish. The results (reported in Arellano-Aguilar \& Macías Garcia, 2008) showed also that exposed fish were smaller than controls, and that the development of their ornamental fins did not resemble that of their fathers, whereas it was significantly heritable in their control half sibs $\left(h_{2}=2 \mathrm{~m}=1.13 \pm 0.096\right)$.

\subsection{Early exposure to sub-lethal dosages of MeP impairs male ornamentation; does it affect male attractiveness?}

Having established that embryonic exposure to low concentrations of MeP negatively affects male ornamentation and courtship behaviour, we evaluated whether this would have reproductive consequences. Test were conducted in aquaria divided into three compartments, the central one being occupied by a female and the lateral compartments being used to place one control and one exposed male in each. Both experimental and control females were tested in their preferences. We recorded frequency and duration of female visit and frequency of copulation attempts for $20 \mathrm{~min}$, and found that both types of females had significant preferences for control males, thus we conclude that exposed males were less attractive to female than their control half-siblings (Arellano-Aguilar \& Macías Garcia, 2008).

\subsection{Sub-lethal exposure to MeP affects the individual; are there population consequences over the long term?}

The following experiment was designed to find out whether the exposure to $0.005 \mu \mathrm{g}$ of MeP had consequences at the population level and through generations. We used this concentration because it appears, from our experiments summarised above, that it has no direct effects on the individuals, but when pregnant females are exposed to this concentration, their offspring grow to be less attractive and court less vigorously than control fish. We collected pregnant females from a location in the upper Lerma basin (Salazar, $19^{\circ} 18.33^{\prime} \mathrm{N}, 9^{\circ} 23.35^{\prime} \mathrm{W}$ ), and all the experiments were conducted on their progeny in the laboratory. Each generation was kept in aquaria only until the females gave birth, when all adults were removed and their descendants left to constitute the next generation. In this way we equalled one generation with one cohort. For example, the offspring born from females collected in the field (parental generation, or P), were separated from their mothers and were considered generation F1. We did not use the females from the field as the parental generation in order to avoid the potential effects of unrecorded variables. Members of F1 were distributed into a control and an experimental (exposed) group. Once they reached adulthood (at 90 days of age) experimental fish were exposed to food laced with $0.005 \mu \mathrm{g}$ of $\mathrm{MeP} / \mathrm{g}$ of dry weight.

First we verified the results of the original experiments. As in the previous report (and in Arellano-Aguilar \& Macías Garcia, 2008) we also measured morphological characters and 


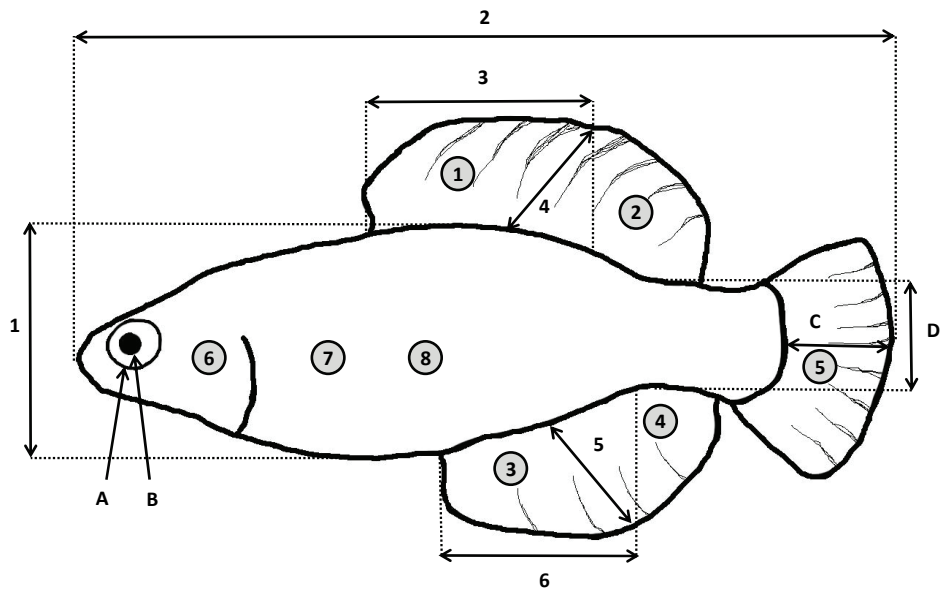

Fig. 3. Morphological measures of Girardinichthys multiradiatus and, within circles, the places where colour (reflectance) was measured by spectrophotometry. Numbers denote the measures that have been systematically found to influence female preferences, and letters indicate measures not known to influence female mate choice.

the attractiveness of the males, with the difference that here we did not use a half-sibling protocol, as we were interested in assessing the effects at the population level. Since the halfsibling protocol reduces the genetic variance between individuals, it is reasonable to expect differences between the two experiments. To confirm whether males exposed prenatally to sub-lethal concentrations of $\mathrm{MeP}$ grow to be morphologically unattractive adults, we followed the protocol used by González Zuarth \& Macías Garcia (2006), and measured in males and females six attributes historically associated with female mate choice (1 to 6 in Fig. 3), and four not associated with it (A to D). The measures were then entered into a principal components analysis (PCA). This protocol was repeated for three generations.

The first component of the PCA (PC1; 74.18\% variance explained) gave large loadings to measures related to fish size, whereas the second component (PC2; 20.84\% variance explained) reflected sexual dimorphism. Together these components explained most of the morphological variance in our experiments (95.02\%; Fig. 3). An ANOVA revealed that fish varied significantly in their PC1 scores $\left(\mathrm{F}_{1,219}=53.82, p=0.000\right)$. The difference between sexes in the PC1 was also significant $\left(\mathrm{F}_{1,219}=48.23, p=0.000\right)$, with females being normally larger as in most viviparous fish. A decrease in size (PC1) among the three generations was significant in females $\left(\mathrm{F}_{1,143}=57.05, p=0.000\right)$ and males $\left(\mathrm{F}_{1,75}=9.05, p<0.001\right)$, and there was also a significant interaction between generation and sex (generation $X$ sex; $F_{1,219}=5.33$, $p=0.005$; Fig. 4) implying that females (whose size is tightly related to fecundity) become smaller in captivity. There was also a significant effect of generation in the PC2 of females $\left(\mathrm{F}_{1,143}=8.30, p<0.001\right)$, whose morphology became increasingly different from that of males.

More direct comparisons of size showed that the relative depth (the ratio of measures 1/2) decreased across generations in both females $\left(\mathrm{F}_{1,143}=26.80, p=0.000\right)$ and males $\left(\mathrm{F}_{1,75}=6.77\right.$, $p<0.005)$, but the relative fin size decreased significantly only in males $\left(\mathrm{F}_{1,75}=20.03, p=0.000\right)$, where it is beyond the ecological optimum by the action of female mate choice (Macías Garcia et al., 1994). Unexpectedly, tail size decreased across generations in both females 
$\left(\mathrm{F}_{1,143}=35.14, p=0.000\right)$ and males $\left(\mathrm{F}_{1,75}=17.62, p<0.001\right)$. There was no significant difference in the eyes' measurements. All the differences over the three generations were due to a significant reduction in size. In addition, experimental females in the second generation were significantly smaller than control females $\left(\mathrm{F}_{1,31}=4.70, p=0.038\right.$; Fig. 4$)$.

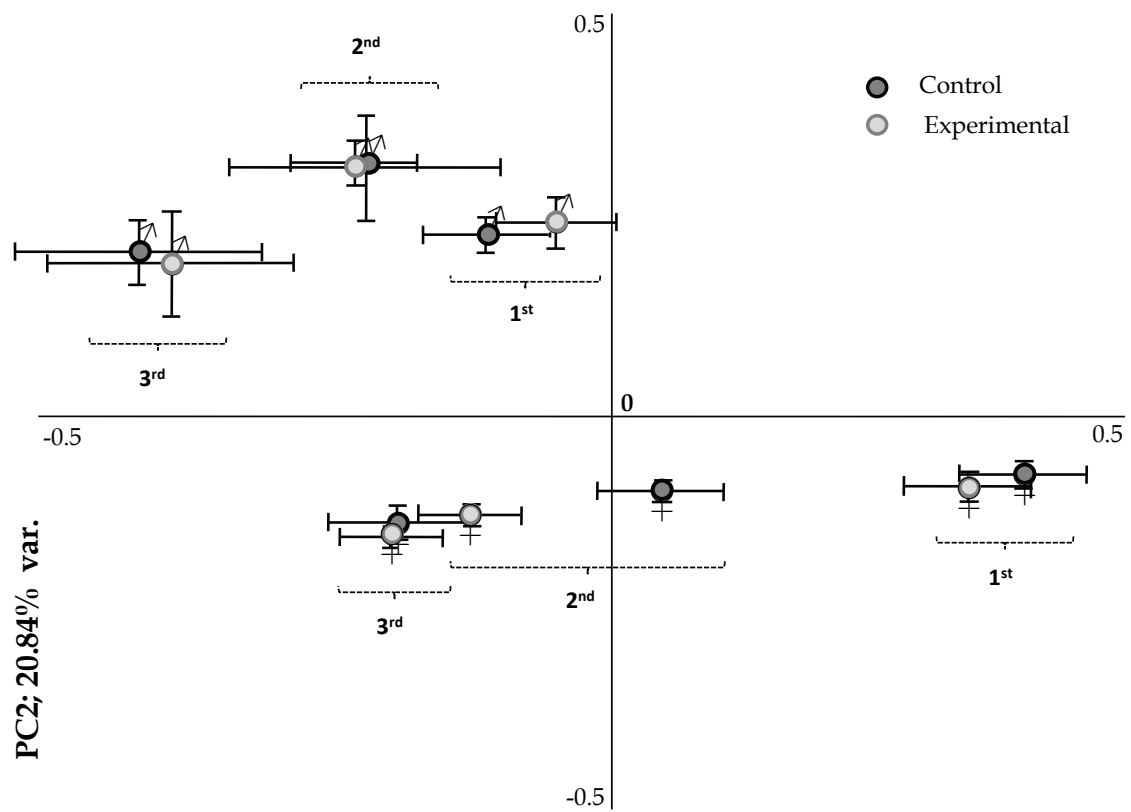

PC1; 74.18\% var.

Fig. 4. Principal Component Analysis (PCA) of body measures. The first principal component captured most of the variance in size, and the second reflects sexual dimorphism. There was a decrease in size across generations in both sexes, and it was significantly large for females (the larger sex, where fecundity is related to size) in the second generation.

Fish colour was measured with a spectrophotometer and assessed with appropriate software (Spectra Suite). We analysed the UV $(360-400 \mu \mathrm{m})$, yellow $(500-630 \mu \mathrm{m})$ and total chroma $(360-740 \mu \mathrm{m})$ reflectance measured at eight different regions of the body and fins (see Fig. 3). The areas measured and the regions of the spectrum selected were chosen following previous studies showing their relevance for sexual selection. The UV reflectance decreased significantly on the third generation $\left(\mathrm{F}_{1,227}=189.75, p=0.000\right)$, in both sexes $\left(\mathrm{F}_{1}\right.$, $\left.{ }_{227}=24.72, p=0.000\right)$, and was also lower in the experimental group $\left(F_{1,227}=4.01, p=0.046\right)$ than in control fish. The carotenoid (yellow) colour of the dimorphic fins showed an unexpected significant increase among generations; fin yellow reflectance was higher in the third generation in both males and females $\left(F_{1,227}=208.57, p=0.000\right)$. Still, prenatal exposure to $\mathrm{MeP}$ also affected dimorphic yellow chroma, with the fins of experimental males showing a reduced reflectance in the yellow region than those of control males $\left(F_{1,227}=5.03, p=0.026\right)$. Finally, total chroma decreased among generations $\left(\mathrm{F}_{1,227}=16.91, p=0.000\right)$ but was significant higher in control $\left(\mathrm{F}_{1,227}=6.52, p=0.001\right)$ than in experimental males. 


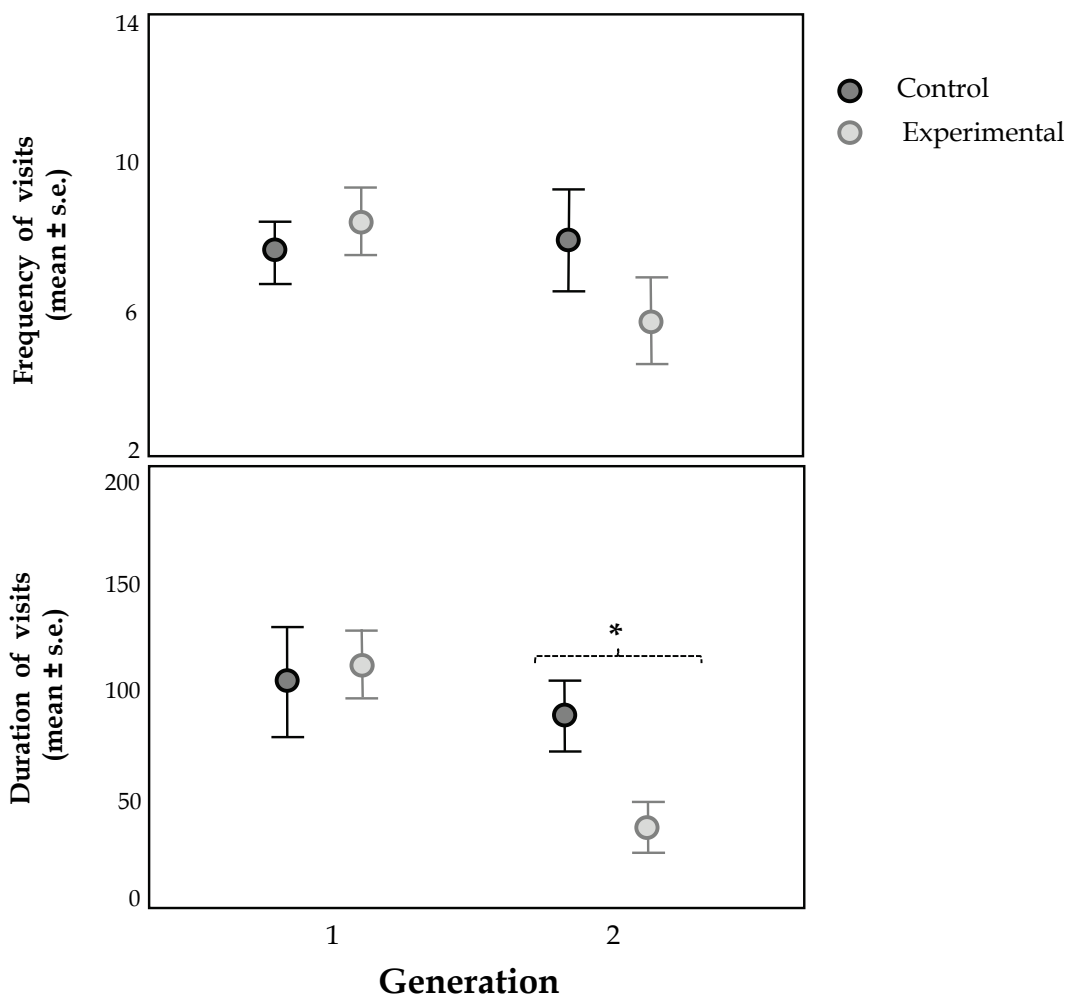

Fig. 5. Females in the first and second generation made as many visits to experimental and to control males, but their visits to the former were shorter in the second generation.

Attractiveness was as assessed by measuring female preference in dichotomous tests as before. We found (Fig. 5) that in the first generation there were no differences in the frequency $\left(t_{1,71}=-1.01, p>0.05\right)$ or the duration $\left(t_{1,71}=-0.30, p>0.05\right)$ of the visits by the females (control or experimental) to the males; females visited for as long, and as frequently, the experimental and the control males. The results in the second generation were different. Females again made the same number of visits to both types of male $\left(t_{1,34}=3.90, p>0.05\right)$, but their visits to the control males were on average longer $\left(t_{1}, 196.12=2.01, p=0.047\right)$, and thus spent significantly more time next to control than to experimental males $\left(t_{1,34}=3.82, p=0.002\right)$. This seems to reflect a cumulative effect of the pesticide. The females did not discriminate between males in the first generation, but could distinguish in the second generation and preferred to remain associated with control males. It is interesting to remember that there were no differences in morphology between treatments in this generation, thus we propose that the female preference for control males in the second generation was due to differences in behaviour, in particular to courtship displays.

We followed two strategies to analyse the demographic data from this experiment. First we analysed the original data, and then we estimated population dynamics projections using a 
random re-sampling procedure. We did find a decrease in the population size over the generations, seemingly due selection to adapt to captive conditions. This pattern was confirmed by our re-sampling analysis, which seems to suggest, nevertheless, that the experimental populations decrease more rapidly than the control ones (Fig. 6). However, there were some demographic patterns that differ between treatments. The number of offspring born was similar in control and in experimental tanks in every generation ( $\mathrm{F}=0.74$, $p=0.39$ ), but experimental offspring had a higher early mortality rate $(<1$ month old) than control fish $(\mathrm{F}=6.63, p=0.011)$. We also found that the frequency of fish with malformations (such as scoliosis, lordosis, etc.) in the experimental group was significantly higher than in the control group (Fig. 7; F=5.52, $p=0.020$ ).

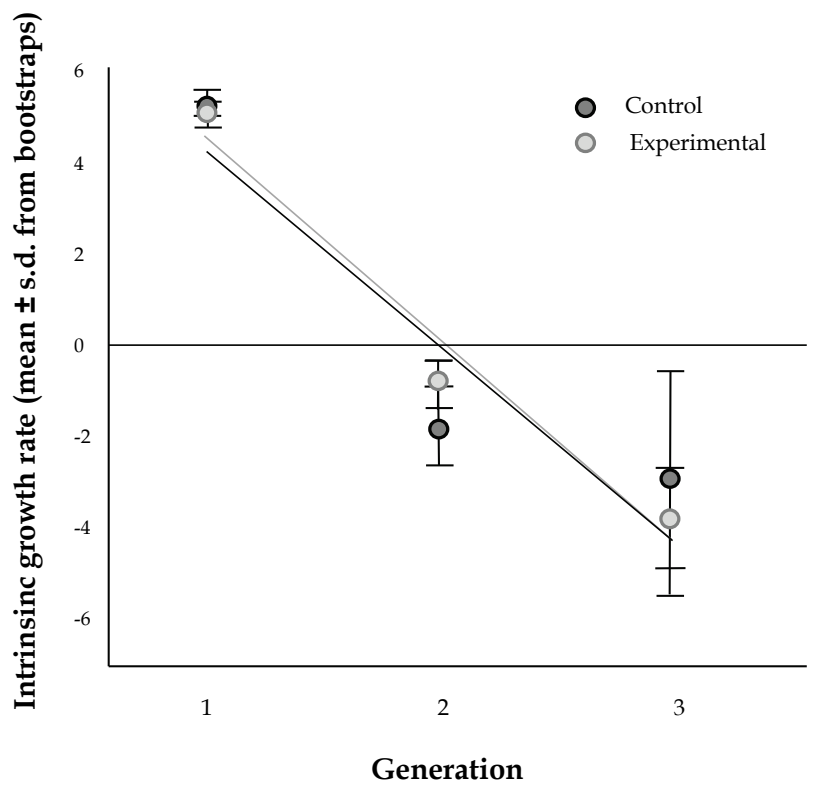

Fig. 6. The intrinsic growth rate of captive populations of Girardinichthys multiradiatus (confidence intervals from 1000 bootstrapped simulations) decrease from between generations due to selection to the aquarium conditions, but also in response to intra-ovary exposure to MeP. A similar pattern was observed in fecundity, which decrease between generations, was lower for exposed fish (and decreased faster for experimental fish).

\section{Conclusions}

It is uncertain wheter alternative technologies will ever be developed to help producing large crops without the need of pesticides. Genetic manipulation may hold a key, yet for the moment we are forced to use pesticides and to try to minimise their collateral, unintended effects. One traditional approach to assessing the risks inherent to pesticide use has involved measuring the consequences of exposure to lethal concentrations -at least to $\mathrm{LC}_{50}$ - and has largely negleted the effects of lower concentrations. Indeed, it is impractical to evaluate 


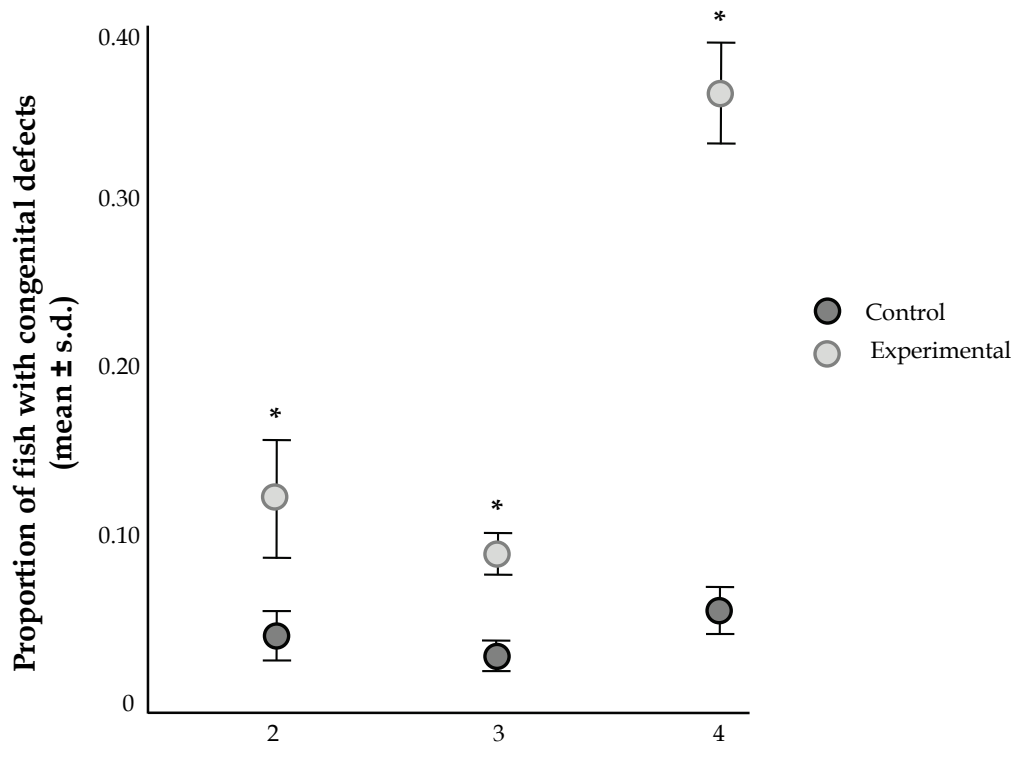

Generation

Fig. 7. The proportion of offspring born with deformities (mostly scoliosis) was significant larger $\left(^{*}\right)$ in fish exposed to $\mathrm{MeP}$ before birth than in controls. In the latter the incidence of those malformations remained below $10 \%$ in all generations, whereas in experimental fish it increased to more than one third in the last generation.

natural populations exposed to sub-lethal concentrations of pesticides, not least because effects of such exposure may be subtle, and subtle effects require large sample sizes to be detected. We propose that bioassays relying on ecologically relevant complex behaviours may facilitate the task. Unlike the relatively simple, reactive behaviours normally included in toxicological tests, the complex sequences of behaviour involved in courtship or foraging activities constitute the integrative outcome of many physiological and developmental processes, and are thus more likely to provide evidence of toxicological damage. Their study, however, requires consideration of Behavioural-Ecological theory, and the use of tools from Population Ecology and Genetics. Our initial results studying the effect of methyl-parathion on a sexually dimorphic fish are encouraging. We have shown that prenatal exposure to a sub-lethal concentration of the insecticide increases the probability that offspring are born with defects. Surviving offspring grow to become unattractive adults, the males are shunned by their females and the females' fecundity is diminished. The effects accumulate through generations and together can compromise the survival of populations. This is likely to be a general effect in species where sexual selection is intense, and demonstrates the need to incorporate Behavioural Ecology and the study of sub-lethal effects in the growing field of Ecotoxicology. 


\section{Acknowledgements}

Founding for this project was provided by the University's research program PAPIIT (grant IN221506) to CMG. IB and OAA were recipients of scholarships the Mexican Science Council (CONACyT). We thank E. Ávila Luna for logistical support, and M. E. Gonzalez, M. Cervantes and N. Villasana from the Animal Health Verification Center (CENAPA) for help with biochemical essays.

\section{References}

Abu-Qare, A.; Abdel-Rahman, A.; Kishk, A. \& Abou-Donia, B (2000). Placental transfer and pharmacokinetics of a single dermal dose of $\left[{ }^{14} \mathrm{C}\right]$ methyl parathion in rats, Toxicological Sciences, 53, 1, 5-12, ISSN 1096-6080

Allendorf, F. \& Luikart, G. (2007). Conservation and the genetics of populations, Blackwell Publishing, ISBN 4051-2145-9, UK

Andersson, M. (1994). Sexual Selection. Princeton University Press, ISBN 069103344 7, Princeton, New Jersey, USA

Andersson, M. \& Simmons, L. (2006). Sexual selection and mate choice, Trends in Ecology and Evolution, 21, 6, 296-302, ISSN 0169-5347

Arellano-Aguilar, O. \& Macías Garcia C. (2008). Exposure to pesticides impairs the expression of fish ornaments reducing the availability of attractive males, Proceedings of the Royal Society, 275, 1640, 1343-1351, ISSN 0962-8452

Arellano-Aguilar, O. \& Macías Garcia C. (2009). Effects of methyl parathion exposure on development and reproduction in the viviparous fish Girardinichthys multiradiatus, Environmental Toxicology, 24, 2, 178-186, ISSN 1520-4081

Baerends, G. (1976). The functional organization of behaviour, Animal Behaviour, 24, 726-738, , ISSN 0003-3472

Bailey, N.; Macías Garcia, C. \& Ritchie, M. (2007) Beyond the point of no return? A comparison of genetic diversity in captive and wild populations of two nearly extinct species of Goodeid fish reveals that one is inbred in the wild, Heredity, 98, 6, 360-367, ISSN 0018-067X

Barron, M. (2002). Environmental contaminants altering behaviour, In: Behavioural ecotoxicology, Giacomo Dell'Omo (Ed.), 167-186, John Wiley \& Sons Ltd., ISBN 0471-96852-8, Chichester, West Sussex, UK

Basolo, A. (2004). Variation between and within the sexes in body size preferences, Animal Behaviour, 68, 1, 75-82, ISSN 0003-3472

Bjerselius, R.; Lundstedt-Enkel, K.; Olsén, H.; Mayer, I. \& Dimberg, K. (2001) Male goldfish reproductive behaviour and physiology are severely affected by exogenous exposure to 17ß-estradiol, Aquatic Toxicology, 53, 2, 139-152, ISSN 0166-445X

Bondarenko, S. \& Gan, J. (2004). Degradation and sorption of selected organophosphate and carbamate insecticides in urban stream sediments, Environmental Toxicology and Chemistry, 23, 8, 1809-1814, ISSN 0730-7268

Bonfanti, P.; Colombo, A.; Orsi, F.; Nizzetto, I.; Andrioletti, M.; Bacchetta, R.; Mantecca, P.; Fascio, U.; Vailati, G. \& Vismara, C. (2004). Comparative teratogenicity of 
chlorpyrifos and malathion on Xenopus laevis development, Aquatic Toxicology, 70, 3 , 189-200, ISSN 0166-445X

Boone, S. \& Chambers, J. (1996). Time course of inhibition of cholinesterase and aliesterase activities, and nonprotein sulfhydryl levels following exposure to organophosphorus insecticides in Mosquitofish (Gambusia affinis), Fundamental and Applied Toxicology, 29, 2, 202-207, ISSN 1096-6080

Börjeson, H., \& Norrgren, L. (1997). M74 syndrome: a review of potential etiological factors, In: Chemically induced alterations in functional development and reproduction of fishes, Rosalind M. Rolland, R. M.; Gilberston, M.; \& E. Peterson, R. E. (Eds.), (153-166), SETAC Technical Publications Series, ISBN 1-880611-19-8, Pensacola, FL., USA.

Castillo, C.; Montante, M.; Dufour, L.: Martinez, M.; Jimenez-Capdeville, M. (2002). Behavioural effects of exposure to endosulfan and methyl parathion in adult rats, Neurotoxicology and Teratology, 24, 6, 797-804, ISSN 0892-0362

Contreras-Balderas, S. (2005). Conservation Status of Mexican Freshwater Viviparous Fishes, In: Viviparous Fishes, Uribe, M. \& Grier, H. (Eds.), 415-423, New Life Publications, ISBN 0-9645058-5-1, Mexico

Cothran, R.; Greco, R. \& Relyea, R. (2010). No evidence that a common pesticide impairs female mate choice in a freshwater amphipod, Environmental Toxicology, 35, 3, 310314, ISSN 1520-4081

Cotton, S.; Fowler, K. \& Pomiankowski, A. (2004). Do sexual ornaments demonstrate heightened condition-dependent expression as predicted by the handicap hypothesis?, Proceedings of the Royal Society, 271, 1541, 771-783, ISSN 0962-8452

Crandall, K.; Posada, D. \& Vasco, D. (1999). Effective population sizes; missing measures and missing concepts, Animal Conservation, 2, 4, 317-319, ISSN 1367-9430

Curtis, C. \& Stoddard, P. (2003). Mate preference in female electric fish, Brachyhypopomus pinnicaudatus, Animal Behaviour, 66, 2, 329-336, ISSN 0003-3472

Darwin, C. (1871). The descent of man and selection in relation to sex, John Murray, Albemmarle Street, London UK

Das, P. \& John, G. (1999). Induction of sister chromatid exchanges and chromosome aberrations in vivo in Etroplus suratensis (Bloch) following exposure to organophosphorus pesticide, Toxicology Letters, 104, 1-2, 111-116, ISSN 0378-4274

De la Vega Salazar, M.; Martínez-Tabche, L. \& Macías Garcia, C. (1997). Bioaccumulation of methyl parathion and its toxicology in several species of the freswater community at Ignacio Ramirez dam in México, Ecotoxicology and Environmental Safety, 38, 53-62, ISSN 0147-6513

De la Vega-Salazar, M. \& Macías Garcia, C. (2005). Principal Factors in the Decline of the Mexican Endemic Livebearing Fishes (Goodeinae: Goodeidae), In: Viviparous Fishes, Uribe, M. \& Grier, H. (Eds.), 505-513, New Life Publications, ISBN 0-9645058-5-1, Mexico

Fanta, E.; Rios, S’A. F.; Romão, S.; Vianna, C.C.A. \& Freiberger, S. (2003). Histopathology of the fish Corydoras paleatus contaminated with sublethal levels of organophosphorus in water and food, Ecotoxicology and Environmental Safety, 54, 2, 119-130, ISSN 01476513 
Fisher, H.; Wong, B. \& Rosenthal, G. (2006). Alteration of the chemical environment disrupts communication in a freswater fish. Proceedings of the Royal Society B, 273, 1951, 11871193, ISSN 0962-8452

Fisher, R. (1930). The genetical theory of natural selection. Oxford University Press, ISBN 019 850440 3, Great Clarendon Street, Oxford NY, USA

Futuyma, J.D. (1998). The evolution of behavior, In: Evolutionary Biology, Douglas J. Futuyma (Ed.), 586-601, Sinauer Associates, Inc., ISBN 0-87893-189-9, Sunderland, Massachusetts, USA.

Garcia, S.; Abu-Qare, A.; Meeker-O'Connell, W.; Borton, A.; Abou-Donia, M. (2003). Methyl parathion: a review of health effects, Journal of Toxicology and Environmental Health, Part B, 6, 2, 185-210, ISSN 1660-4601

González Zuarth, C. \& Macías Garcia, C. (2006). Phenotypic differentiation and pre-mating isolation between allopatric populations of Girardinichthys multiradiatus. Proceedings of the Royal Society, 273,1584, 301-307, ISSN 0962-8452

IUCN. 2010. Red list of threatened species. http://www.iucn.org

Jokanović, M. (2001). Biotransformation of organophosphorus compounds, Toxicology, 166, 3, 139-160, ISSN 0300-483X

Jones, J. \& Reynolds, J. (1997). Effects of pollution on reproductive behaviour of fishes, Reviews in Fish Biology and Fisheries, 7, 4, 463-491, ISSN 0960-3166

Kimura, M. \& Crow, J. (1963). The measurement of effective population number, Evolution, 17, 3, 279-288, ISSN 0014-3820

Kimura, M.; Maruyama, T. Crow, F.J. (1963). The mutation load in small populations, Genetics, 48, 10, 1303-1312, ISSN 0016-6731

Lehner, N.P. (1996). A conceptual model of animal behavior, In: Hanbook of ethological methods Second Edition, Philip N. Lehner (Ed.), 19-23, Cambridge University Press, ISBN 0-521-55405-5, New York, NY., USA.

Leslie, P. (1945). On the use of matrices in certain population mathematics, Biometrika, 183212, ISSN 0006-3444

Li, Q. (2007). New mechanism of organophosphorus pesticide-induced immunotoxicity, Journal of Nippon Medical School, 74, 2, 92-105, ISSN 1345-4676

Little, E. (1990). Behavioral toxicology: stimulating challenges for a growing discipline, Environmental Toxicology and Chemistry, 9, 1, 1-2, ISSN 0730-7268

Macías Garcia, C. \& Burt de Perera, T. (2002). Ultraviolet-based female preferences in a viviparous fish, Behavioral Ecology and Sociobiology, 52, 1, 1-6, ISSN 0340-5443

Macías Garcia, C. \& Saborío, E. (2004). Sperm competition in a viviparous fish, Environmental Biology of Fishes, 70, 211-217, ISSN 0378-1909

Macías Garcia, C. (1994). Social behaviour and operational sex ratios in the viviparous fish Girardinichthys multiradiatus, Copeia, 4, 919-925, ISSN 0045-8511

Macías Garcia, C; Jimenez, C. \& Contreras, B. (1994). Correlational evidence of a sexuallyselected handicap, Behavioral Ecology and Sociobiology, 35, 253-259, ISSN 0340-5443

Markman, S.; Leitner, S.; Catchpole, C. \& Müller, C. (2008). Pollutants increase song complexity and the volume of the brain area HVC in a songbird, PLoS ONE, 3, 2, ISSN 1932-6203 
Merilä, J. \& Sheldon, B. (1999). Genetic architecture of fitness and nonfitness traits: empirical patterns and development of ideas, Heredity, 83, 2, 103-109, ISSN 0018-067X

Nimmo, R. \& McEwen C. (1994). Pesticides, In: Handbook or ecotoxicology, Peter Calow (Ed.), 619-667, Blackwell Science Ltd., ISBN 0-632-03573-0, Main Street, Malden, USA

Parker, M. \& Goldstein, M. (2000). Differential toxicities of organophosphate and carbamate insecticides in the nestling European starling (Sturnus vulgaris), Archives of Environmental and Contamination Toxicology, 39, 2, 233-242, ISSN 0090-4341

Price, D. (2005). The genetic considerations in the conservations of freshwater viviparous fish, In: Viviparous Fishes, Uribe, M. \& Grier, H. (Eds.), 351-364, New Life Publications, ISBN 0-9645058-5-1, Mexico

Reynolds, J. \& Jones, J. (1999). Female preference for preferred male is reversed under low oxygen conditions in the common goby (Pomatoschistus microps), Behavioural Ecology, 10, 2, 149-154, ISSN 1045-2249

Rieman, B. \& Allendorf, F. (2001). Effective population size and genetic conservation criteria for bull trout, North American Journal of Fisheries Management, 21, 4, 756-764, ISSN 0275-5947

Sarma, S.; Nandini, S.; Gama-Flores, J. \& Fernández-Araiza, M. (2001). Population growth of Euchlanis dilatata (Rotifera): combined effects of methyl parathion and food (Chlorella vulgaris), Journal of Environmental Science Health, B, 36, 1, 43-54, ISSN 03601234

Secondi, J.; Hinot, E.; Djalout, Z.; Sourice, S. \& Jadas-Hécart, A. (2009). Realistic nitrate concentration alters the expression of sexual traits and olfactory male attractiveness in newts, Functional Ecology, 23, 4, 800-808, ISSN 0269-8463

Seehausen, O.; van Alphen, J. \& Witte, F. (1997). Cichlid fish diversity threatened by eutrophication that curbs sexual selection. Science 277, 5333, 1808-1811, ISSN 01934511

Skalski, J.; Ryding, K. \& Millspaugh, J. (2005). Wildlife demography: analysis of sex, age, and count data. Elsevier Academic Press, ISBN-13: 978-0-12-088773-6, USA

SNIARN (2006). El medio ambiente en México 2005: en resumen. Secretaria del Medio Ambiente y Recursos Naturales, ISBN 968-817-777-6, México

Toft, G. \& Baatrup, E. (2003). Altered sexual characteristics in guppies (Poecilia reticulata) exposed to 17 $\beta$-estradiol and 4-tert-octylphenol during sexual development, Ecotoxicology and Environmental Safety, 56, 2, 228-237, ISSN 0147-6513

Toft, G.; Edwards, T.; Baatrup, E. \& Guillette, L. Jr. (2003). Disturbed sexual characteristics in male mosquitofish (Gambusia holbrooki) from a lake contaminated with endocrine disruptors, Environmental Health Perspectives, 111, 5, 695-701, ISSN 0091-6765

Uribe, M. \& Grier, H. (2005). Viviparous Fishes. New Life Publications, ISBN 0-9645058-5-1, Mexico

Vittozzi, L.; Fabrizi, L.; Consigliko, E. \& Testai, E. (2001). Mechanistic aspects of organophosphorothionate toxicity in fish and human, Environment International, 26, 3, 125-129, ISSN 0160-4120

Walker, C. (1998). Biomarker strategies to evaluate the environmental effects of chemicals, Environmental Health Perspectives, 106, 2, 613-620, ISSN 0091-6765 
Walker, C.; Hopkin, S.; Sibly, R. \& Peakall, D. (2006). Biomarkers, In: Principles of ecotoxicology, C. Walker, S. Hopkin, R. Sibly, D. Peakall (Eds.), 159-160, Taylor \& Francis Group, ISBN 978-0-8493-3635-5, Boca Raton, FL., USA.

Welsh, J.M. \& Hanselka, W.C. (1972). Toxicity and sublethal effects of methyl parathion on behavior of Siamese fighthing fish (Betta splendens), The Texas Journal of Science, 23, 4, 519-529, ISSN 0040-4403

Yom-Tov, Y. \& Geffen, E. (2006). Geographic variation in body size: the effects of ambient temperature and precipitation., Oecologia, 148, 2, 213-218, ISSN 0029-8549

Zahavi, A. (1975). Mate selection- a selection for a handicap, Journal of Theoretical Biology, 53, 205-214, ISSN 0022-5193 


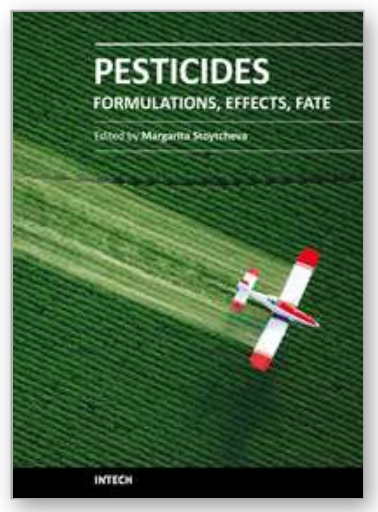

\author{
Pesticides - Formulations, Effects, Fate \\ Edited by Prof. Margarita Stoytcheva
}

ISBN 978-953-307-532-7

Hard cover, 808 pages

Publisher InTech

Published online 21, January, 2011

Published in print edition January, 2011

This book provides an overview on a large variety of pesticide-related topics, organized in three sections. The first part is dedicated to the "safer" pesticides derived from natural materials, the design and the optimization of pesticides formulations, and the techniques for pesticides application. The second part is intended to demonstrate the agricultural products, environmental and biota pesticides contamination and the impacts of the pesticides presence on the ecosystems. The third part presents current investigations of the naturally occurring pesticides degradation phenomena, the environmental effects of the break down products, and different approaches to pesticides residues treatment. Written by leading experts in their respective areas, the book is highly recommended to the professionals, interested in pesticides issues.

\title{
How to reference
}

In order to correctly reference this scholarly work, feel free to copy and paste the following:

Irene Barbosa-valero, Omar Arellano-Aguilar and Constantino Macías Garcia (2011). Organophosphorous Pesticides Exacerbate the Demographic Consequences of Intersexual Selection in Fish, Pesticides Formulations, Effects, Fate, Prof. Margarita Stoytcheva (Ed.), ISBN: 978-953-307-532-7, InTech, Available from: http://www.intechopen.com/books/pesticides-formulations-effects-fate/organophosphorous-pesticidesexacerbate-the-demographic-consequences-of-intersexual-selection-in-fis

\section{INTECH}

open science | open minds

\author{
InTech Europe \\ University Campus STeP Ri \\ Slavka Krautzeka 83/A \\ 51000 Rijeka, Croatia \\ Phone: +385 (51) 770447 \\ Fax: +385 (51) 686166 \\ www.intechopen.com
}

\author{
InTech China \\ Unit 405, Office Block, Hotel Equatorial Shanghai \\ No.65, Yan An Road (West), Shanghai, 200040, China \\ 中国上海市延安西路65号上海国际贵都大饭店办公楼 405 单元 \\ Phone: +86-21-62489820 \\ Fax: +86-21-62489821
}


(C) 2011 The Author(s). Licensee IntechOpen. This chapter is distributed under the terms of the Creative Commons Attribution-NonCommercialShareAlike-3.0 License, which permits use, distribution and reproduction for non-commercial purposes, provided the original is properly cited and derivative works building on this content are distributed under the same license. 